\title{
Transneuronal Regulation of Protein Synthesis in the Brain-Stem Auditory System of the Chick Requires Synaptic Activation
}

\author{
Richard L. Hyson and Edwin W Rubel \\ Hearing Development Laboratories, Department of Otolaryngology, University of Washington, Seattle, Washington 98195
}

\begin{abstract}
The cellular mechanisms by which afferents influence their target neurons were investigated using a slice preparation of the chick brain-stem auditory system. Each brain slice contained portions of the auditory nerve and the secondorder auditory nucleus, nucleus magnocellularis (NM), bilaterally. NM neurons on one side of the slice were stimulated either orthodromically, via activation of the ipsilateral auditory nerve, or antidromically, via electrical stimulation of their axons. NM neurons on the other side of the slice were not stimulated and served as a within-animal control population. Evoked activity was monitored extracellularly in all preparations. Orthodromic activation of NM neurons for either 1.5 or $3.5 \mathrm{hr}$ resulted in enhanced protein synthesis by these neurons. This result is similar to those of previous in vivo experiments (Steward and Rubel, 1985; Born and Rubel, 1988). When slices were maintained in a medium having low $\mathrm{Ca}^{2+}$ and high $\mathrm{Mg}^{2+}$ concentrations, both synaptic transmission from the auditory nerve to NM and also the difference in protein synthesis between the stimulated and unstimulated sides of the brain were blocked. Antidromic activation of NM neurons did not enhance protein synthesis, but rather resulted in reliably less synthesis by the stimulated cells. Together, these results suggest that activity-dependent release of some "trophic" substance from the auditory nerve is necessary for this form of transneuronal regulation. Electrical activity of the postsynaptic neuron per se is not sufficient for increasing protein synthesis in these cells.
\end{abstract}

It is generally accepted that the integrity and activity of sensory afferents play important roles in the development of the nervous system. This conclusion has been supported by experiments that have utilized a variety of methodological approaches, including (1) environmental manipulations (e.g., dark rearing), (2) manipulations of the peripheral sensory accessory structures (e.g., eyelid suture), (3) removal of the end organ, and (4) transection of sensory nerves. Although these varied manipulations may have different effects on the subject's sensory "experience," in common, they all presumably alter the activity of the afferent sensory fibers. Such manipulations, particularly early in life, have been shown to alter several aspects of neural structure and

\footnotetext{
Received Oct. 21, 1988; revised Jan. 5, 1989; accepted Jan. 16, 1989.

This work was supported by NIH-NINCDS grants NS 24516 and NS 07906 We would like to thank G. MacDonald and J. Debel for technical assistance and D. Born, T. Carew, R. Code, D. Durham. E. Overholt, D. Sanes, P. Schwartzkroin P. Schwindt, and J. Truman for comments on earlier versions of the manuscript. Correspondence should be addressed to Richard L. Hyson, Hearing Development Laboratories, Department of Otolaryngology, RL-30, University of Washington, Seattle, WA 98195

Copyright (c) 1989 Society for Neuroscience $0270-6474 / 89 / 082835-11 \$ 02.00 / 0$
}

function. For example, in the auditory system, deprivation, and deafferentation have been shown to alter neuronal structure (Webster and Webster, 1977; Feng and Ragowski, 1980; Parks, 1981; Smith et al., 1983), metabolic activity (Lippe et al., 1980; Durham and Rubel, 1985; Steward and Rubel, 1985; Born and Rubel, 1988), electrophysiological responses (Moore and Irvine, 1981; Brugge et al., 1985) and auditory-guided behavioral capacities (Kerr et al., 1979; Knudsen et al., 1984). Similar results have been observed in every sensory system thus far examined (e.g., Weisel and Hubel, 1963, 1965; Globus, 1975; Gottlieb, 1976; Mistretta and Bradley, 1978; Movshon and van Sluyters, 1981; Sherman and Spear, 1982). Despite this ubiquitous finding of the importance of afferent activity during development, little is known of the cellular mechanisms that underlie this form of transneuronal regulation of neural structure and function.

The fact that afferents influence the development of their target organs is not restricted to sensory systems but is a general property of the developing organism (Harris, 1981). The most frequently examined instance of neuronal regulation of the target organ has been at the neuromuscular junction. Deafferentation of skeletal muscle results in several changes in the acetylcholine rcccptor system, sodium conduction mechanisms, and resting membrane potential of the muscle (Guth, 1968; Cowan, 1970; McArdle, 1983). Similar changes have been observed when afferents are silenced pharmacologically (Lømo and Rosenthal, 1972; Pestronk et al., 1976; Lavoie et al., 1977), suggesting that activity of the presynaptic neurons regulate these properties of the muscle. Some of the changes after deafferentation, such as increased extrajunctional sensitivity to acetylcholine and resting membrane potential depolarization, have been reversed or attenuated by electrical stimulation of the muscle fiber (Lomo and Rosenthal, 1972; Lømo and Westgaard, 1975). This suggests that activity of the muscle per se may be responsible for regulating some properties of the muscle. However, the fact that, in most cases, the effects of denervation are not completely reversed by electrical stimulation of the muscle suggests that some other aspect(s) of nerve-muscle interaction play an important role.

Centrally, where even less is known about the cellular mechanisms underlying afferent regulation of target neurons, the brainstem auditory system of the chicken has been a useful preparation for beginning to investigate these processes. This model system is relatively simple and bilaterally symmetrical, allowing for "experimental" and "control" tissue in the same animal. Second-order neurons in nucleus magnocellularis (NM) receive their sole excitatory input from the ipsilateral auditory nerve (Parks and Rubel, 1978). Unilateral removal of the cochlea results in the cessation of action potentials in the ipsilateral 
auditory nerve and NM (Born and Rubel, 1984). When a unilateral cochlea removal is performed on young chickens, dramatic changes in the postsynaptic NM neurons have been shown to occur. A few days after cochlear removal there is a decrease in the number of NM neurons on the ipsilateral side, and the remaining neurons are reduced in size (Born and Rubel, 1985). Within only hours after cochlea removal, changes in the NM neurons' metabolic activity are observed (Durham and Rubel, 1985; Steward and Rubel, 1985). One of these rapid changes is a decrease in protein synthesis, as assessed by ${ }^{3} \mathrm{H}$-leucine incorporation. By $1 \mathrm{hr}$ after cochlea removal, neurons in the ipsilateral NM make approximately $50 \%$ less protein that those on the normal side. By 3-6 hr after cochlea removal, 2 populations of neurons in the ipsilateral NM can be identified. All neurons show reduced synthesis compared with the intact side, but approximately $30 \%$ of the neurons show a complete cessation of protein synthesis (Steward and Rubel, 1985). This corresponds to the proportion of transneuronal cell death observed several days after cochlea removal (Born and Rubel, 1985). At this later time point, cells showing a cessation of protein synthesis are not observed (E. W Rubel and O. Steward, unpublished observations), suggesting that those that stopped making protein are the neurons which eventually die. These data suggest that the rapid changes in protein synthesis are an early indicator of the later fate of neurons. Thus, the incorporation of ${ }^{3} \mathrm{H}$-leucine serves as a convenient bioassay. Within 1 $\mathrm{hr}$ the decrease in incorporation following receptor removal is predictive of the susceptibility of the tissue to transneuronal changes, and within 3-6 hr it predicts the final disposition of individual neurons.

Recent experiments have taken advantage of this relatively rapid bioassay to show in vivo that afferent activity is essential for the regulation of protein synthesis in the postsynaptic NM neurons. If the auditory nerve is reversibly silenced, by injection of tetrodotoxin (TTX) into the perilymph of the cochlea, changes in protein synthesis, cell size, and cell number are similar to those observed following complete cochlea destruction (Born and Rubel, 1988). Thus, as in the case of the neuromuscular junction, merely silencing the afferent nerve fibers results in many of the same transsynaptic changes in the target as when the nerve is damaged.

Although the TTX experiments point to the crucial role of activity in transneuronal rcgulation of protein synthesis, they do not address the question of what aspect of activity is important for this regulation. Activity of the auditory nerve could influence the metabolic activity of NM neurons through a variety of processes. We can initially break down the range of possible processes into 4 categories: (1) The action of a trophic substance from the auditory nerve terminal, the release of which is dependent on activity of the presynaptic neuron, (2) the action of a trophic substance from the auditory nerve whose release is not dependent on evoked synaptic release, (3) events associated with the generation of action potentials by the postsynaptic NM neurons, or (4) recurrent processes subsequent to the activation of the NM neurons. The present experiments evaluate these possibilities using a slice preparation of the chick's brain-stem auditory system. We compared the effects of orthodromic and antidromic activation of NM neurons, thereby dissociating between above hypotheses 1 or 2 versus 3 or 4 . We further assessed the role of evoked synaptic release (hypotheses 1 vs 2) by preventing synaptic release by maintaining slices in a low $\mathrm{Ca}^{2+}$ / high $\mathrm{Mg}^{2+}$ medium. Our results suggest that the transneuronal regulation of protein synthesis in NM neurons is the result of the postsynaptic action of a "trophic substance" released from active auditory nerve terminals.

\section{Materials and Methods}

\section{Brain slice preparation}

Slice preparation. All brain slices used in these experiments were obtained from 5-15d posthatch chicks (White Leghorn, $\mathrm{H}+\mathrm{N}$ ) that were hatched and reared in our colony either at the University of Virginia or at the University of Washington. Chicks were decapitated, and a large coronal section was cut through the skull and brain using a razor bladc. This section was then transferred to a petri dish containing oxygenated artificial cerebrospinal fluid (ACSF) at room temperature. In this dish, the brain stem was carefully dissected free from the cranium. The ventral surface of the resulting brain-stem chunk was then affixed to the stage of a tissue slicer (Fredrick-Haer, OTS-3000) with cyanoacrylate glue. Warmed gelatin ( $25 \%$ in ACSF) was injected under the lateral aspects of the ventral surface in order to provide additional support. Coronal slices were cut at $300 \mu \mathrm{m}$. Slices containing bilaterally symmetrical portions of the auditory nerve and nucleus magnocellularis were then transferred to a recording chamber. Preparation of the slice in this manner took approximately $10-15 \mathrm{~min}$.

Chamber construction. Chambers were handmade and were modeled after the one described by Oertel $(1983,1985)$. A 1.4-cm-diameter well was carved out of a piccc of $0.3 \mathrm{~cm}(1 / 8$ inch) thick magnetic rubber (McMaster-Carr). A 0.3-cm-wide exit trough was carved from this well, extending $2.5 \mathrm{~cm}$ from the edge of the well and then angling at approximately $90^{\circ}$ and continuing an additional $1.5 \mathrm{~cm}$ and terminating in a 0.5 -cm-diameter well. The carved rubber was then affixed to a 50 $\times 75 \mathrm{~mm}$ microscope slide with paraffin. Excess paraffin was scraped from the wells and troughs. ACSF flowed directly into the large well through 20 gauge tubing adapters and exited through the troughs to the small well, being drawn off either by suction or by a peristaltic pump.

General procedures and media. The slice was placed in the well of the recording chamber on a piece of lens tissue and was held in place by a piece of nylon mesh secured with metal clips. For all slices, ACSF flowed through the chamber at $3.5 \mathrm{ml} / \mathrm{min}$. Standard ACSF consisted of (in $\mathrm{mM}$ ): $\mathrm{NaCl}, 130 ; \mathrm{KCl}, 3 ; \mathrm{CaCl}_{2}, 2 ; \mathrm{MgCl}_{2}, 2 ; \mathrm{NaHCO}_{3}, 26 ; \mathrm{NaH}_{2} \mathrm{PO}_{4}$, $1.75 ; d$-glucose, 10 . For the low calcium/high magnesium expcriments the medium consisted of $0.5 \mathrm{mM} \mathrm{CaCl}_{2}$ and $5 \mathrm{mM} \mathrm{MgCl}_{2}$ (Hackett et al., 1982) with other concentrations remaining the same as the standard ACSF. The ACSF was oxygenated and warmed prior to inflow. The temperature of the medium as it flowed through the chamber was approximately $34^{\circ} \mathrm{C}$.

\section{Electrophysiological procedures}

Orthodromic stimulation. The general procedures are outlined in Figure 1. For orthodromically stimulated slices, a bipolar Ag stimulating electrode (twisted Teflon-coated Ag wires) was placed on the stump of the auditory nerve on one side of the slice. Stimulation was continuous at a rate of $10 \mathrm{~Hz}$ using $50 \mathrm{~V}, 20 \mu \mathrm{sec}$ pulses. In pilot experiments, no synaptic failure was observed with $10 \mathrm{~Hz}$ stimulation rate. Groups of slices were unilaterally stimulated for either 1.5 or $3.5 \mathrm{hr}$.

Antidromic stimulation. Antidromic stimulation of NM neurons was achieved by electrically stimulating their axons as they approached midline in the crossed dorsal cochlear tract. In order to limit activation to NM on one side of the slice, a cut through this tract at midline was first made. Stimulation parameters were the same as in the $1.5 \mathrm{hr}$ orthodromically stimulated slices.

Axotomy control. The cut through the crossed dorsal cochlear tract in the antidromically stimulated slices essentially axotomized NM neurons on both sides of the slice. To control for possible confounding effects of axotomy in the antidromic stimulation experiments, slices which were also cut at midline were stimulated orthodromically for 1.5 hr.

Recording. In each slice, field potentials were periodically monitored to confirm the effectiveness of stimulation. Glass micropipettes, filled with ACSF (0.5-5 M $\Omega$ ) were visually placed on NM using a Leitz micromanipulator. The electrical signals were amplified (WPI M-707 or Neurodata IR-283), displayed on an oscilloscope (Tektronics 5111, RM565 or 2230), and stored on FM tape (Racal 4DS).

Direct comparisons of the extracellular activity evoked by orthodromic versus antidromic stimulation were made in slices in which 


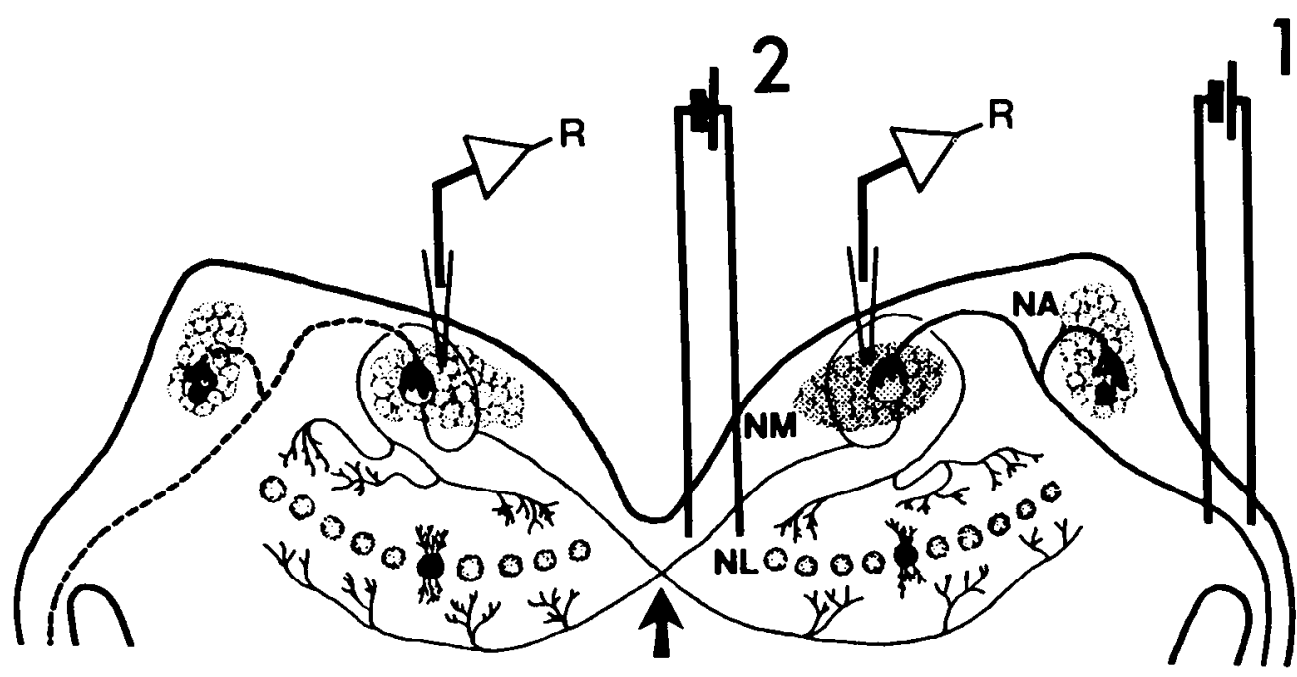

Figure 1. Schematic of the brain-stem auditory system of the chick displaying the general methodology. Neurons in NM were stimulated either orthodromically $(l)$, via activation of the auditory nerve, or antidromically (2), via activation of their axons as they approached midline. Recording electrodes $(R)$ were periodically placed on NM to monitor evoked activity. Arrow indicates the location of axon transection in the antidromic and control orthodromic stimulation slices. protein synthesis was not assessed. For 6 slices, stimulating electrodes were placed both on the ipsilateral auditory nerve and on the axons of NM neurons in the crossed dorsal cochlear tract. A single recording electrode (1-5 M $\Omega$ ) was then placed on NM and the field potentials evoked by the 2 methods of stimulation were recorded. Intracellular recordings from NM neurons also were obtained from these 6 slices and 2 additional slices. These recordings were made to evaluate whether antidromic activity invaded the soma. For these recordings, glass micropipettes (50-100 M $\Omega$, filled with $4 \mathrm{M} \mathrm{K}^{+}$acetate) were advanced into NM using a Leitz micromanipulator. Cell penetration was assisted by AC pulses through the recording electrode. The spikes evoked by the 2 methods of stimulation were then compared.

\section{Anatomical procedures}

Leucine incorporation. During the last $0.5 \mathrm{hr}$ of stimulation, $0.1 \mathrm{mCi}$ of ${ }^{3} \mathrm{H}$-leucine (40-60 $\mathrm{mCi} / \mathrm{mm}$ leucine, ICN Radiochemicals) in $25 \mathrm{ml}$ of ACSF was circulated through the chamber using a recirculating system cmploying a multichannel peristaltic pump (Ismatec Reglo). After leaving the chamber, the ACSF was pumped into a reservoir, where it was reoxygenated before being pumped back into the chamber.

Histological procedures. At the end of the leucine-incorporation period, slices were briefly rinsed by immersion in leucine-free ACSF at room temperature and then fixed by immersion in Bouin's solution for $2 \mathrm{hr}$. Fixed slices were transferred to $70 \%$ ethanol overnight, and, following dehydration in $95 \%$ ethanol, they were embedded in methacrylate (LKB Historesin). The slice was sectioned coronally at 3 or $6 \mu \mathrm{m}$ and mounted on acid-washed, chrome-alum subbed slides. Slides were dipped in photographic emulsion (Kodak NTB2 diluted 1:1 with distilled water) and exposed for $1-4$ weeks at $4^{\circ} \mathrm{C}$. Autoradiograms were developed (Kodak D-19), fixed (Kodak Rapidfix without hardener), and counterstained with thionin.

Data analysis. The autoradiographs were analyzed using a digital image analysis system (Bioquant System IV, R\&M Biometrics). The video image of the section, observed under a $100 \times$ oil objective (Leitz PL Fluatar 1.32 N.A.), was digitized and displayed on a monilor. The experimenter first adjusted the light, contrast, and threshold settings so as to delineate areas of the tissue covered by developed silver grains from unlabeled areas. Once these settings were determined, they remained constant for all measurements of a given slice. The experimenter would then trace the outline of individual NM neurons, and the computer would calculate the proportion of soma area covered by developed silver grains. This measure was calculated for 30-40 NM neurons on each side of the same tissue sections. That is, in each slice there was an "experimental" (stimulated) magnocellular nucleus and on the contralateral side a "control" (unstimulated) nucleus. One to three sections were measured for each slice. Cells were analyzed only if they had clear cytoplasmic and nuclear outlines with the Nissl stain. Only sections in the middle third of the slice were quantified. For between-group comparisons, the percent difference in labeling between the stimulated and unstimulated sides was calculated for each slice [(stimulated - unsti- mulated)/unstimulated], and a between-group analysis of variance was performed using these difference scores.

For the autoradiographic analysis of protein synthesis to be valid, 2 conditions must be met: (1) the method of analysis must accurately reflect the amount of ${ }^{3} \mathrm{H}$-leucine in the tissue, and (2) the ${ }^{3} \mathrm{H}$-leucine in the tissue must be incorporated into protein and not exist simply as free amino acid. The accuracy of the grain analyzing technique was evaluated measuring grain densities of plastic autoradiographic standards (3-1 10 $\mathrm{nCi} / \mathrm{mg}$, Amersham) dipped in emulsion and developed in the same way as the tissue sections. The analysis of grain density using the Bioquant image-analysis routine revealed a linear relationship between calculated grain density and the radioactivity of the standards. The values of $R^{2}$ ranged from 0.974 to 0.996 . Although linear, the slope of the relationship varied with changes in the threshold level or light intensity (see Fig. 2). Increasing the threshold value (i.e., using a more liberal criteria for determining what constitutes a "grain") resulted in a greater slope. When the threshold criteria was made too liberal (not shown), the linear relationship was lost as a plateau was reached at high radioactivities. The linear range using this technique extended beyond the useful range for manual counting of individual grains (Born and Rubel, 1988). Over the useful range for manual counting, the $R^{2}$ between manual and automated grain counts ranged from 0.932 to $0.980 \mathrm{de}-$ pending on the automated threshold setting. For the measurements of autoradiograms, the light, brightness, contrast, and threshold were set in an attempt to maximize the signal-to-noise of grains over background, so as to achieve the steepest possible slope while maintaining a linear relationship.

To assess if the labeling observed reflected incorporated leucine, 2 slices maintained in media containing the protein synthesis inhibitor cycloheximide (100 $\mu \mathrm{g} / \mathrm{ml}$, cf. Lipton, 1987), but otherwise treated in the same way as experimental slices, were processed in parallel with a slice maintained in normal medium. The parallel processing of these tissues assured that the emulsion batch, exposure time, and development were identical. The results showed that the amount of labeling over NM neurons as compared with background labeling (areas within the fourth ventricle) was reduced by approximately $95 \%$ in the cycloheximide slices. Thus, the vast majority of labeling observed over NM neurons in the present series of experiments appears to represent incorporated leucine and not free amino acid. This result is not surprising since formaldehyde-based fixatives do not bind free amino acids to the tissue (Rogers, 1979).

\section{Results}

\section{Electrophysiology}

Orthodromic stimulation. Figure 3 shows averaged field potentials from NM ipsilateral $(A)$ and contralateral $(B)$ to stimulation of the auditory nerve. Unilateral stimulation evoked postsynaptic responses in NM neurons ipsilateral to the stimulated 
Figure 2. Grain density of radiographic standards processed for autoradiography, as measured by video image analysis. Grain density is defined as the proportion of area covered by silver grains. Each linear-regression line represents the results of this analysis when the "threshold" was set for different values.

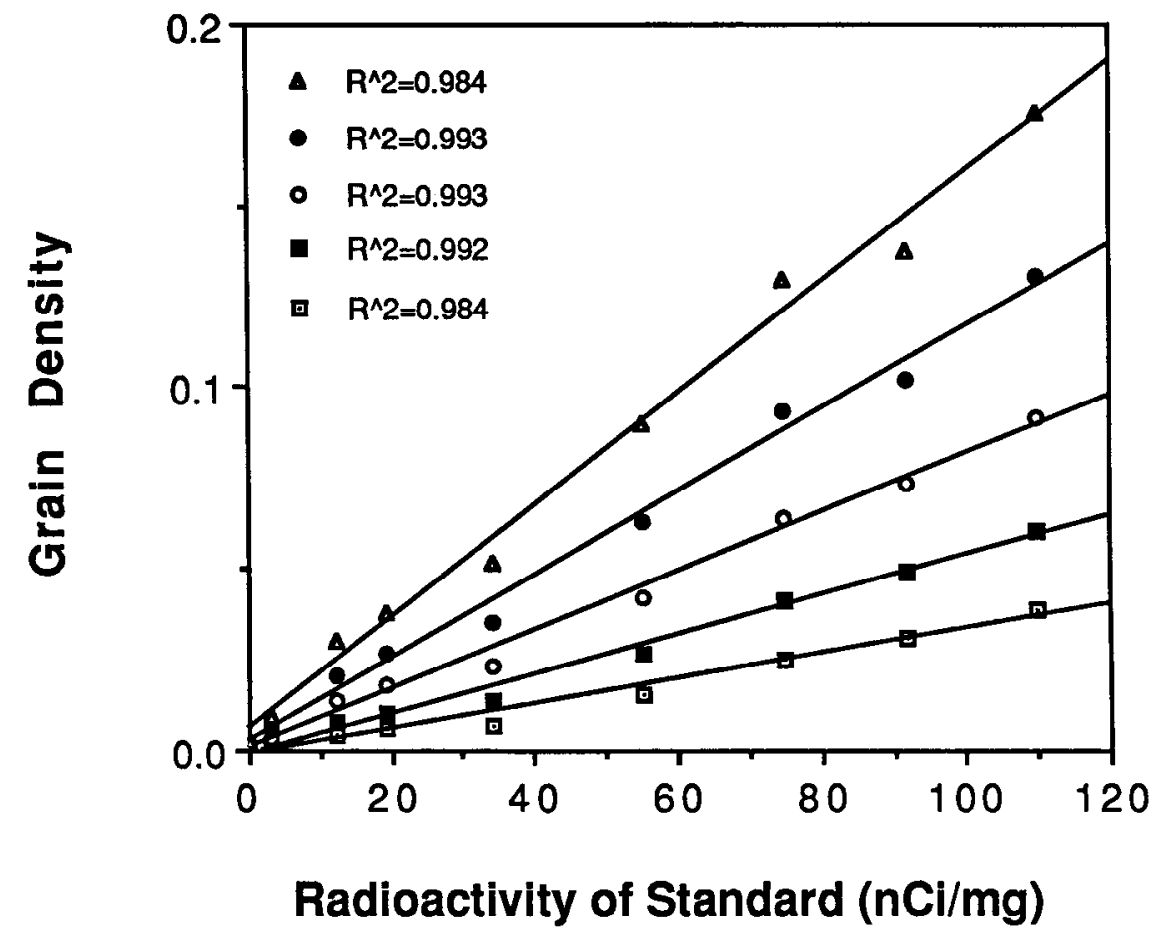

activated antidromically may be a conservative estimate since the stimulus artifact often obscured antidromic spikes. Analysis of tape recordings from 9 cells activated by both orthodromic and antidromic stimulation revealed no reliable difference in the height of the evoked spike $[t(8)=0.28, p>0.7]$. Measurements of other spike parameters were not made due to the obstruction of the antidromic spikes by the stimulus artifact. Together, these electrophysiological analyses indicate that our orthodromic and antidromic stimulation procedures activate similar populations of NM neurons and that the action potentials evoked by these different procedures appear to invade the cell body to the same extent.

\section{Protein synthesis}

Orthodromic stimulation. Orthodromic activation of NM neurons resulted in a greater density of labeling over neurons on the stimulated side of the slicc. This was truc whether sliccs were unilaterally stimulated for 1.5 or for $3.5 \mathrm{hr}$. Figure 5 shows representative autoradiographs from a slice that was stimulated for $1.5 \mathrm{hr}$. Greater labeling over stimulated neurons is apparent. Analysis of grain densities over NM neurons confirm this visual impression. Figure 6 presents the distribution of grain densities for individual NM neurons for one slice that was stimulated for $1.5 \mathrm{hr}$. The distribution of grain densities is obviously higher on the stimulated side of the slice. For 8 of the 9 orthodromically stimulated slices, significantly greater labeling was observed on the stimulated side ( $t$ tests, $p \mathrm{~s}<0.01$ in each case). In the ninth slice, the labeling on the stimulated side was higher, but the difference did not reach statistical significance.

The autoradiographic technique does not allow for directly comparing the labeling across subjects because of variability in such factors as emulsion thickness and exposure times. In order to combine distributions across slices, density measurements were first converted to a $z$-score based on the mean and SD of the cells on the stimulated side of the section (Born and Rubel, 1988). The resulting $z$-score distributions for stimulated and and $2(9 \%)$ could be activated only antidromically, while an orthodromically elicited action potential as compared with an antidromically elicited action potential from the same cell. However, not all neurons were activated by both orthodromic and antidromic stimulation: of 22 intracellularly studied cells from 8 slices, $4(18 \%)$ could be activated only orthodromically $(73 \%)$ were activated in both directions. The proportion of cells 

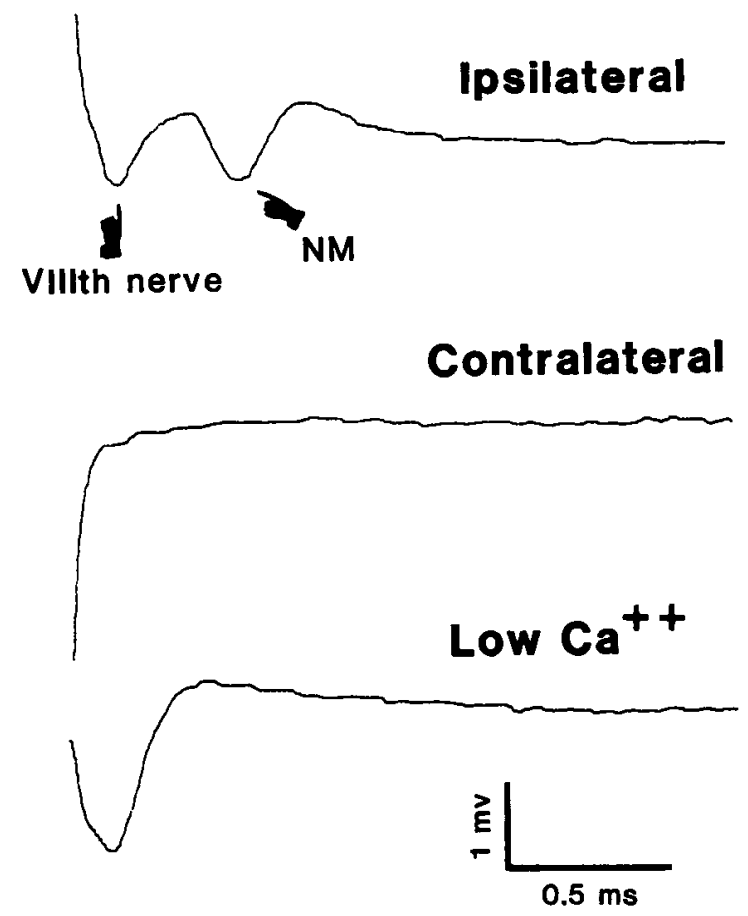

Figure 3. Field potentials recorded in NM during unilateral stimulation of the auditory nerve. Ipsilateral, Recording from NM ipsilateral to stimulation, showing potentials corresponding to the afferent volley and postsynaptic response from NM neurons. Contralateral, Recording from NM contralateral to stimulation, confirming that auditory nerve innervation is unilateral. $\mathrm{Low} \mathrm{Ca}^{++}$, Recording from NM ipsilateral to stimulation when the slice was maintained in a low $\mathrm{Ca}^{2+} / \mathrm{high} \mathrm{Mg}^{2+}$ medium, showing only an afferent volley but no postsynaptic response.

unstimulated sides of the orthodromically stimulated slices are shown in Figure $7(A, 1.5 \mathrm{hr} ; B, 3.5 \mathrm{hr})$. It should be noted that the distributions of grain densities in these normalized data appear different than those from the individual case represented in Figure 6. The primary cause for this apparent discrepancy is that our $z$-score transform, by definition, forces the density scores on the stimulated side to approach a normal distribution having a mean of zero and a SD of 1 .

For group statistical analysis, the mean absolute grain densities on stimulated versus unstimulated sides were compared using a paired $t$ test. By this analysis, labeling on the stimulated side was significantly greater than that on the contralateral, unstimulated side $[t(4)=3.86, p<0.05,1.5 \mathrm{hr}$ group; $t(3)=$ $12.192, p<0.01,3.5 \mathrm{hr}$ group]. For between-group comparisons (see below), the data from each slice were also transposed to a percent difference score [(mean density over stimulated NM neurons - mean density over unstimulated NM neurons)/mean density over unstimulated NM neurons]. For slices stimulated for $1.5 \mathrm{hr}$, there was an average of $96 \%$ (range, $10-165 \%$ ) greater labeling on the stimulated side. For slices stimulated for $3.5 \mathrm{hr}$, NM neurons on the stimulated side showed a mean of $54 \%$ (range, 44-67\%) greater labeling than those on the unstimulated side. The percent difference scores of the 1.5 versus $3.5 \mathrm{hr}$ groups did not differ reliably (see below).

Low calcium/high magnesium. When slices were maintained in an ACSF having low $\mathrm{Ca}^{2+}$ and high $\mathrm{Mg}^{2+}$ concentrations, no reliable difference in labeling was observed between the stimulated and unstimulated sides of the slice. The $z$-score distribution of grain densities for this group is shown in Figure $7 C$.

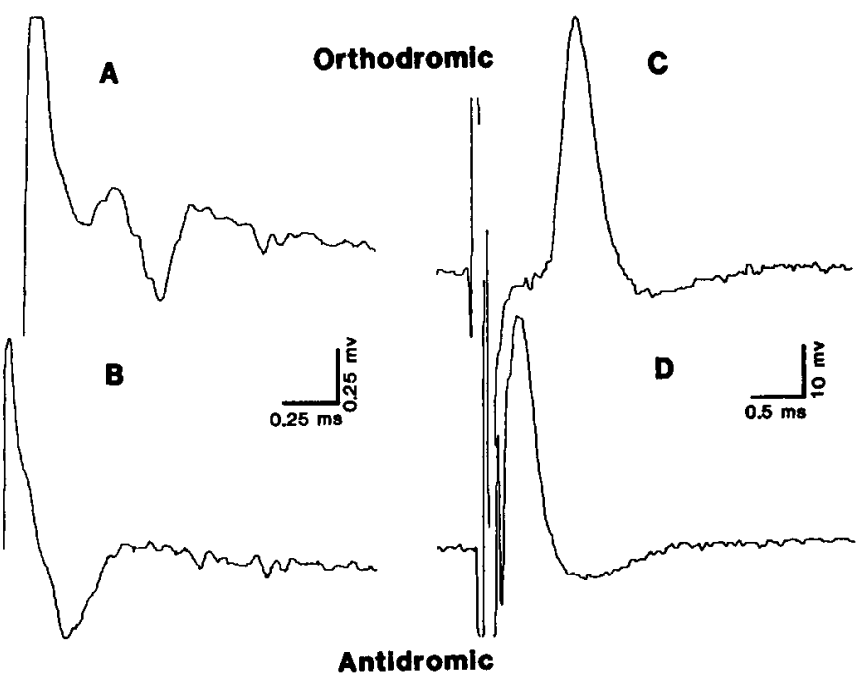

Figure 4. Field potentials $(A$ and $B)$ and intracellular recordings $(C$ and $D$ ) from NM during orthodromic $(A$ and $C)$ or antidromic ( $B$ and $D$ ) stimulation of the same slice/cell. Note the similarity in the magnitudes of the orthodromic and antidromic fields and spikes. Cell in $C$ and $D$ had a resting potential of $65 \mathrm{mV}$.

A mean of $4.5 \%$ less labeling was observed on the stimulated side of the slice (range, -31 to $+23 \%$ ). Using a paired $t$ test, the difference between the mean grain densities on the stimulated and unstimulated sides of the slice did not approach statistical significance $[t(3)=0.72, p>0.5]$.

Antidromic stimulation. When NM neurons were unilaterally antidromically stimulated for $1.5 \mathrm{hr}$, stimulated cells did not make more protein than unstimulated neurons. In fact, unexpectedly, the antidromically stimulated slices showed an average of $30 \%$ (range, $11-52 \%$ ) less amino acid incorporation on the stimulated side than on the unstimulated side. An example of this effect is shown in Figure 5, and the $z$-score distributions of grain densities for the group is shown in Figure $7 D$. The decrease in mean grain densities on the antidromically stimulated vs. unstimulated sides of the slice was statistically significant [paired $t(3)=5.17, p<0.05]$

Midline cut controls. Two slices that were cut at midline and unilaterally stimulated orthodromically showed greater protein synthesis by stimulated NM neurons. For both of these slices, the difference in labeling between the 2 sides was statistically significant $[t$ tests, $p$ s $<0.01]$. These 2 slices showed 27 and $55 \%$ greater grain density on the stimulated side. These results are within the range of differences observed when slices were stimulated orthodromically without prior axotomy of NM neurons at midline (see above). Therefore, the difference in the results of the orthodromic stimulation and antidromic stimulation experiments cannot simply be attributed to axotomy in the antidromic group.

\section{Between-group comparisons}

Between-slice comparisons in absolute levels of labeling are not appropriate using the autoradiographic technique. Thus, it cannot be determined, for example, if the slices maintained in low calcium/high magnesium made less protein than those maintained in standard ACSF. The percent difference in labeling between two sides of a given slice, however, can be used to make comparisons between groups. This value provides an estimate 


\section{ORTHODROMIC}

STIMULATED

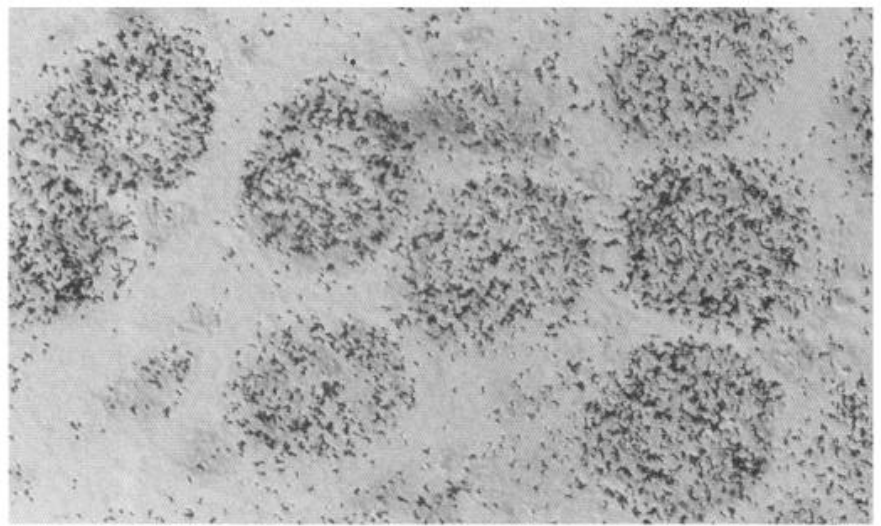

UNSTIMULATED

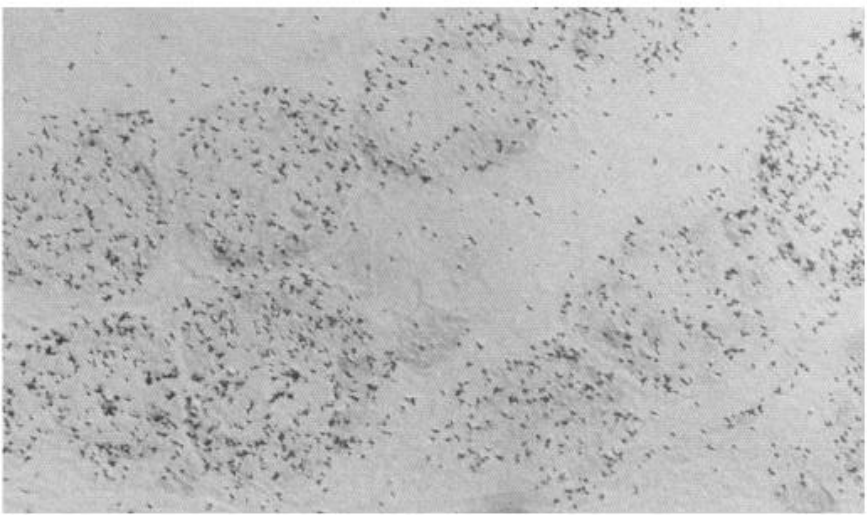

\section{ANTIDROMIC}

\section{STIMULATED}

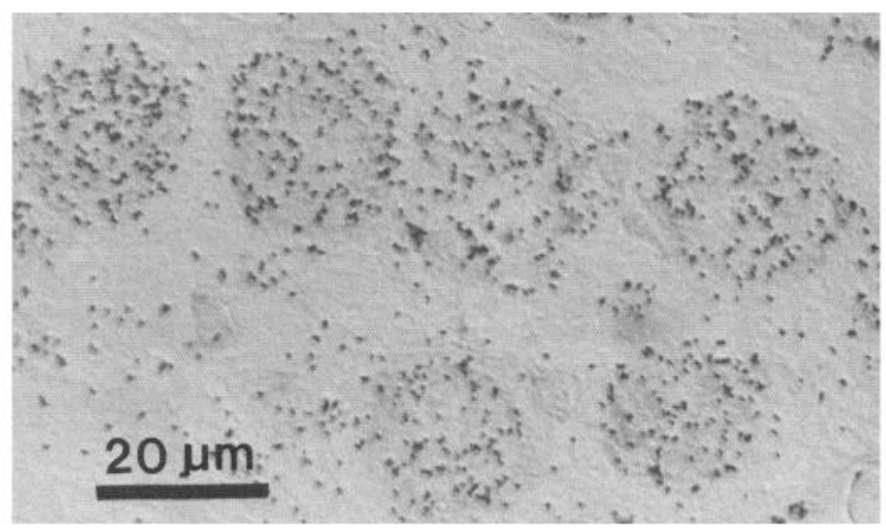

UNSTIMULATED

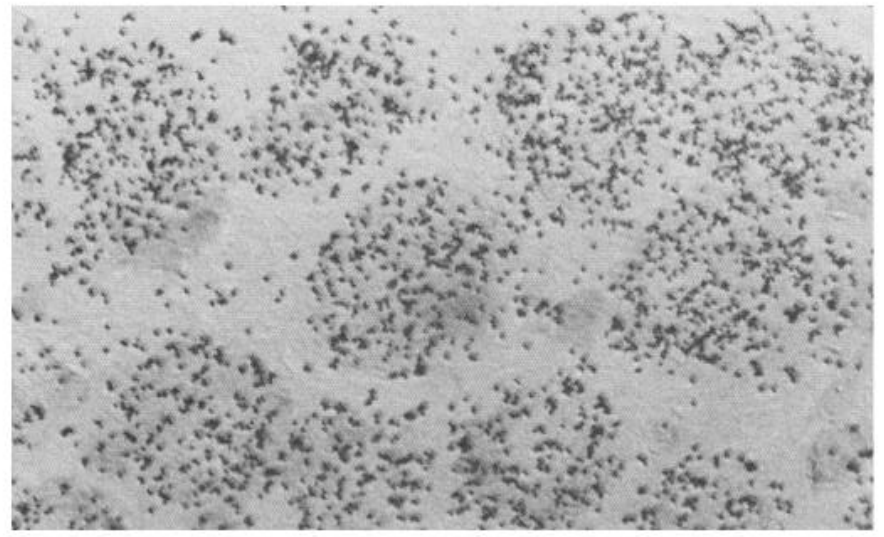

Figure 5. Autoradiographs of stimulated and unstimulated NM neurons. The top photomicrographs are taken from a slice stimulated orthodromically for $1.5 \mathrm{hr}$; the bottom photomicrographs are taken from a slice stimulated antidromically for $1.5 \mathrm{hr}$.

of the degree to which stimulation produces a change in amino acid incorporation with respect to the unstimulated NM neurons treated identically except for the stimulation. These difference scores can legitimately be combined across subjects. Average difference scores from the major experimental groups are plotted in Figure 8. A between-group analysis of variance including both orthodromic stimulation groups, the low $\mathrm{Ca}^{2+} / \mathrm{high} \mathrm{Mg}^{2+}$ group and the antidromic stimulation group revealed a reliable Group effect $[F(3,13)=10.87, p<0.001]$. Post hoc paired comparisons (Neuman-Kuels, $p<0.05$ ) revealed that both orthodromic stimulation groups had a greater difference in labeling between stimulated and unstimulated sides than did either the low $\mathrm{Ca}^{2+} / \mathrm{high}$ $\mathrm{Mg}^{2+}$ group or the antidromic stimulation group. No other comparisons were reliable. For these analyses, the 2 midline-cut orthodromic stimulation slices were included in the $1.5 \mathrm{hr}$ orthodromic group. The same statistical results were obtained when the analyses were performed without including these 2 control subjects.

\section{Discussion}

Orthodromic stimulation of second-order auditory neurons in NM results in enhanced protein synthesis in those neurons. This effect of orthodromic stimulation appears to require calciumdependent synaptic release from the auditory nerve since it is not observed when synaptic transmission is blocked by maintaining the slice in a medium containing low calcium and high magnesium concentrations. Antidromic activation of NM neurons at the same rate does not enhance protein synthesis but, rather, results in less synthesis by the stimulated neurons. Together, these results suggest that the transneuronal up-regulation of protein synthesis requires the action of a trophic substance that is released from active auditory nerve terminals. The nature of this substance and the mechanism of its action are not known, but the increase in protein synthesis is not simply the result of the cascade of events involved in the propagation of action potentials in the postsynaptic neuron.

\section{Methodological considerations}

In this report the incorporation of leucine into protein by NM neurons was used as a bioassay for examining activity-dependent transneuronal regulation. The use of overall protein synthesis as the bioassay for the effects of stimulation was chosen because in vivo analyses have shown that the changes in protein synthesis are an early predictor of the later fate of the neurons 
(Steward and Rubel, 1985). In addition, we feel that the use of the same dependent variable in both in vivo and in vitro experiments provides some confidence that the underlying cellular processes studied in vitro are common to those that occur in the whole animal. Finally, the fact that changes in protein synthesis occur within hours of altering afferent input to these neurons makes an in vitro analysis possible.

Three issues are not addressed by using overall protein synthesis as the dependent measure. First, one cannot determine whether the synthesis of specific proteins was altered or if there was a decrease in the synthesis of all proteins. Second, one cannot determine if afferent activity induces an increase in protein synthesis or if it serves to prevent a decrease in synthesis that occurs when the neuron is deafferented. Third, these data do not distinguish between a direct action on the postsynaptic NM neuron or an indirect one, for example, through an effect on glial cells (Rubel and MacDonald, 1987). These will be important topics for future investigations. However, in the context of the present report, these distinctions are of little importance since our purpose was to further explore the signal(s) underlying transneuronal regulation, rather than to analyze the postsynaptic chain of cellular events per se. Thus, protein synthesis was used only as an example of one (albeit important) cellular property that is regulated by afferent activity.

\section{Orthodromic stimulation}

The result of enhanced protein synthesis by orthodromically stimulated NM neurons is in agreement with previous results of changes in protein synthesis after manipulation of the auditory periphery in chickens. Steward and Rubel (1985) found less protein synthesis in NM on the side ipsilateral to cochlea removal in young chicks but not in adults. Similarly, Born and Rubel (1988) showed that these changes in protein synthesis are observed when auditory nerve action potentials are prevented by infusing tetrodotoxin into the perilymph, which bathes the cochlear hair cells and distal processes of the auditory nerve fibers. The correspondence between the present results and those previously observed in vivo is important in that it suggests that the in vitro slice procedure is a valid means by which to analyze in vivo cellular mechanisms.

The ionic and/or molecular factors accounting for the regulation of protein synthesis after orthodromic stimulation are unknown. In other neural systems, the cellular mechanisms responsible for neuronal "plasticity" often involve the activitation of second-messenger systems (Baudry and Lynch, 1980; Kandel and Schwartz, 1982; Alkon, 1984). For example, in Aplysia, long-term enhancement of synaptic transmission, which accounts for behavioral sensitization, can be produced either by stimulation, application of serotonin, or application of analogs of the second messenger, cAMP. This long-term enhancement of transmission requires protein synthesis during the acquisition phase of the experiment (Schacher et al., 1988), suggesting that increased activity of cAMP results in changes in protein synthesis that contribute to this form of neuronal plasticity.

Such receptor-mediated second-messenger systems may also play a role in the regulation of protein synthesis in NM neurons. The experiments in which slices were maintained in a low $\mathrm{Ca}^{2+}$ / high $\mathrm{Mg}^{2+}$ medium suggest that synaptic release is a necessary condition for this form of transneuronal regulation to occur. The conclusions to be drawn from these experiments, however, are limited on 2 grounds. First, blocking synaptic release does not distinguish between whether the "trophic" signal is the neu-

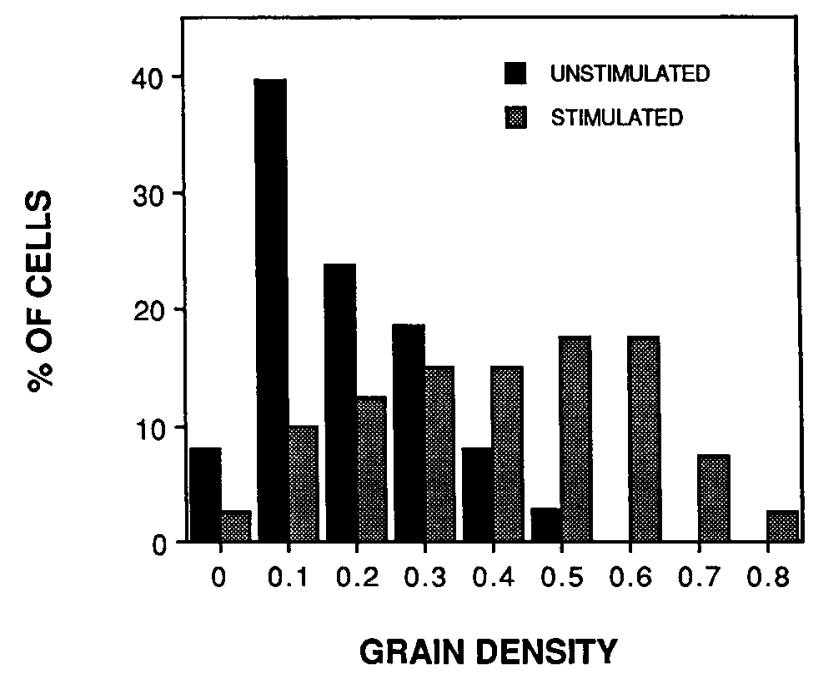

Figure 6. Distribution of grain densities (proportion of soma area covered by grains) of individual NM neurons from a slice stimulated orthodromically for $1.5 \mathrm{hr}$. Neurons on the stimulated side (light bars) show greater labeling than those on the unstimulated side (dark bars).

rotransmitter or some factor(s) co-released with the transmitter. Second, changing the calcium and magnesium concentrations may have direct influences on the postsynaptic neuron. Support for a role of the neurotransmitter comes from recent experiments in which blockade of excitatory amino acid receptors also prevents the enhanced protein synthesis resulting from orthodromic stimulation (Hyson and Rubel, 1988).

The neurotransmitter for the auditory nerve-NM neuron synapse is thought to be an excitatory amino acid. Electrophysiological analyses imply that all 3 categories of excitatory amino acid receptors (NMDA, quisqualate, and kainate) may be present postsynaptically, but synaptic transmission appears to be mediated by one of the non-NMDA types of receptor (Nemeth et al., 1983; Jackson et al., 1985; Martin, 1985). Recently, a number of reports have focused on the possible role of NMDA receptor activation in neuronal "plasticity" during development (Kleinschmidt et al., 1988), in regulating synaptic efficacy (Collingeridge et al., 1983; Harris et al., 1984), and in learning situations (Morris et al., 1986; reviewed by Cotman et al., 1988). Our current experiments are assessing the possible roles of NMDA receptor activation in the regulation of protein synthesis in the brain-stem auditory system of the chick.

\section{Antidromic stimulation}

Unexpectedly, antidromic stimulation of NM neurons resulted in less protein synthesis by the stimulated neurons. This result implies that the enhancement of synthesis caused by orthodromic stimulation is not simply due to those events associated with propagation of action potentials in the postsynaptic neuron. Thus, some aspect of presynaptic activity and cell-cell communication is necessary for the up-regulation of protein synthesis. The finding of decreased protein synthesis as a result of postsynaptic action potentials alone also implies that the upregulation of synthesis by orthodromic activation is even greater than initially believed. That is, since orthodromic stimulation also results in the generation of action potentials in the postsynaptic neurons, in order for it to increase synthesis above baseline, it must also compensate for, or prevent, the decrease 


\subsection{HR ORTHODROMIC}

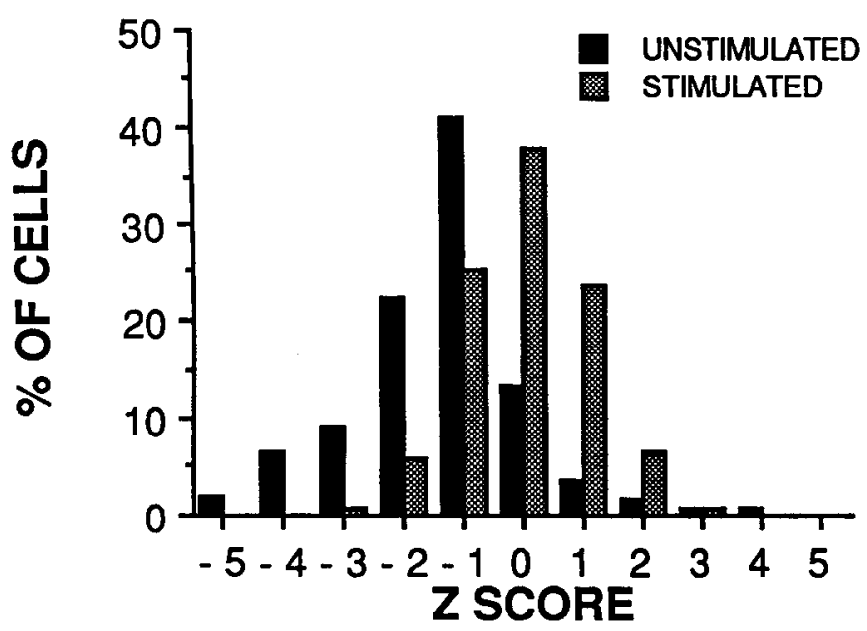

LOW CALCIUM

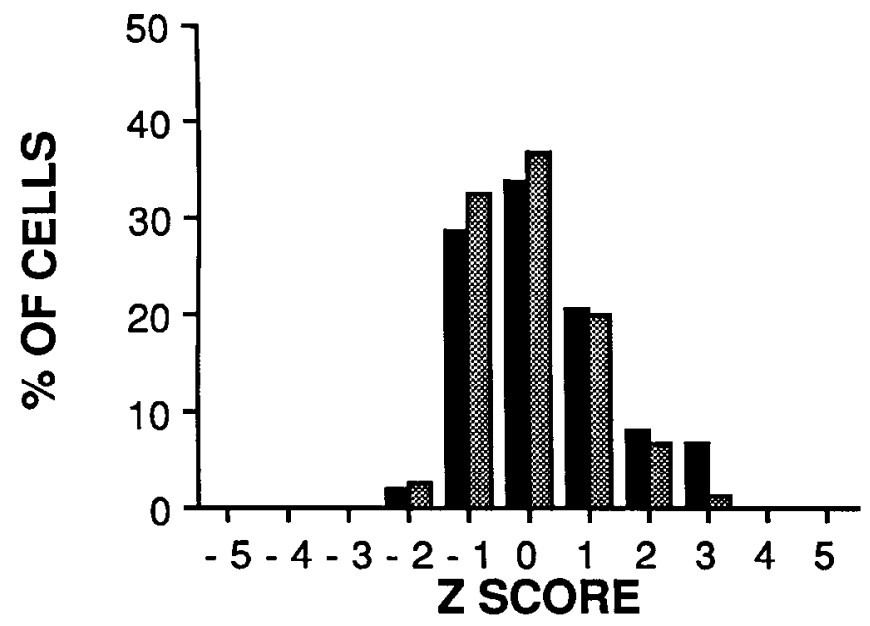

3.5 HR ORTHODROMIC

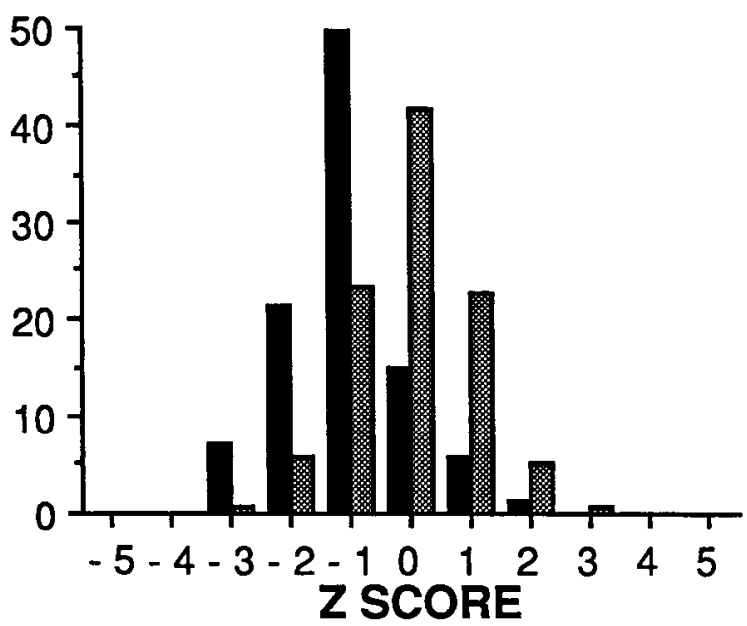

1.5 HR ANTIDROMIC

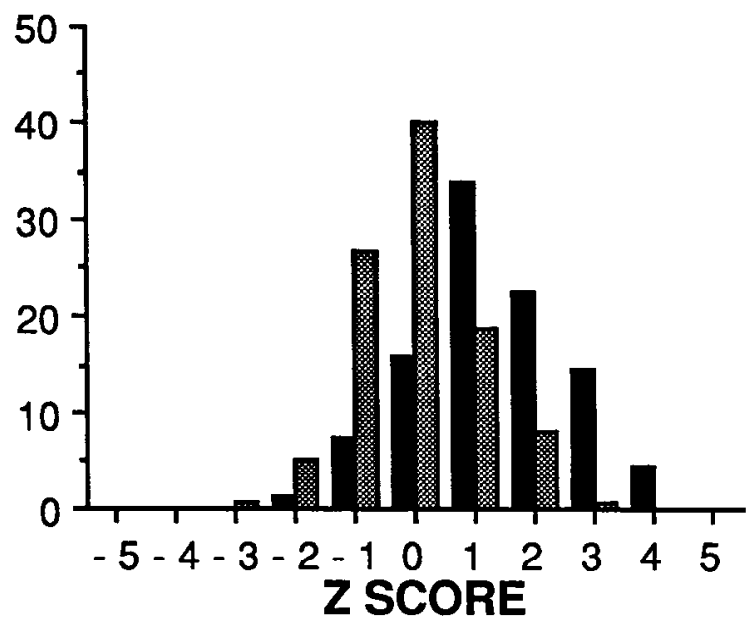

Figure 7. $z$-Score distribution of grain densities for the various groups of slices. $z$-Scores were calculated based on the mean and SD of NM neurons on the stimulated side of the slice. The resulting distributions from individual slices were then pooled to create these group distributions.

in synthesis caused by the action potentials of the postsynaptic neuron.

Previous experiments have also shown decreases in overall protein synthesis after gross electrical stimulation of brain slices. For example, Jones and Mcllwain (1971) reported that stimulation of cortical slices resulted in a reduction in protein synthesis. It is important to note, however, that the method of stimulation used in these experiments was to provide an electrical charge across the entire slice. This method of stimulation, presumably, would directly stimulate a number of fibers, rather than driving neurons synaptically. As such, their entire slice stimulation might be expected to have similar consequences as our antidromic stimulation. By this logic, the results are consistent: Postsynaptic activity, by itself, results in a reduction of protein synthesis.

The ionic and/or molecular factors accounting for the decreased protein synthesis after antidromic stimulation of the NM neuron are unknown. One possible explanation may be a decrease in intracellular $\mathrm{K}^{+}$concentration caused by the generation of action potentials. Along with decreased protein synthesis, Jones and Mcllwain (1971) generally observed corresponding changes in $\mathrm{K}^{+}$concentrations in their stimulated slices. Both of these effects were blocked by addition of TTX to the bath. This result implies that action potentials are necessary for both of these effects to occur. Lipton and colleagues (Lipton and Heinbach, 1978; Lipton and Robacker, 1983) assessed the role of $\mathrm{K}^{+}$levels on protein synthesis by using manipulations known to alter intracellular $\mathrm{K}^{+}$concentration. For example, increasing extracellular $\mathrm{K}^{+}$concentrations resulted in increased intracellular $\mathrm{K}^{+}$concentration and increased protein synthesis in hippocampal slices, while low concentrations of ouabain reduced $\mathrm{K}^{+}$concentration and also reduced protein synthesis. Thus, it is possible that a transient decrease in $\mathrm{K}^{+}$concentration, as a result of action potentials in antidromically stimulated NM neurons, might account for the observed decrease in protein synthesis. The above events, of course, may occur during ortho- 
dromically driven action potentials as well. If so, the factors involved in the up-regulation of protein synthesis resulting from orthodromic stimulation must also compensate for the decrease in synthesis as a result of postsynaptic action potentials.

\section{Afferent regulation of targets}

As noted above, alterations in the activity of sensory afferents result in abnormal development of structure and function of higher order neurons. For example, visual deprivation early in life results in disruption of the segregation of retinal afferents, decreased cell size of LGN neurons and altered electrophysiological responses of neurons to visual stimulation (reviewed by Movshon and van Sluyters, 1981; Sherman and Spear, 1982). In such experiments, visual deprivation was typically achieved by eyelid suture or dark-rearing of the animals. Thus, only visual-evoked activity was prevented, leaving "spontaneous activity" of retinal ganglion cells intact. Even more profound alterations in the segregation of retinal afferents and electrophysiological responses are observed when the spontaneous activity of retinal ganglion cells is reversibly stopped by intraocular injections of TTX (Dubin et al., 1986; Stryker and Harris, 1986). Thus, "spontaneous," as well as stimulus-driven activity, plays an important role in the development of the visual system. Similarly, in the chick auditory system, "spontaneous activity" of auditory nerve fibers plays an important role in regulating postsynaptic neurons in NM. Decreases in protein synthesis, cell size, and cell number are observed in NM neurons when auditory nerve activity is stopped either by injection of TTX into the perilymph (Born and Rubel, 1988) or by removal of the cochlea (Born and Rubel, 1985; Steward and Rubel, 1985). However, changes in cell size and number are not observed when stimulus-driven activity is markedly attenuated without eliminating spontaneous activity, such as after puncturing the tympanic membrane and removing the columella (the avian middle ear ossicle) (Tucci et al., 1987).

Although it is clear that spontaneous activity plays an important role in regulating the structural and functional development of sensory systems, the cellular mechanisms involved in the regulation of postsynaptic neurons by afferent activity are not completely understood. Such transneuronal regulation could be achieved through a variety of processes. At the neuromuscular junction, for example, regulation of the postsynaptic target (the muscle) appears to depend, to a great extent, on the activity of the muscle per se. Electrical stimulation of the muscle reverses or attenuates several of the effects of denervation (Lomo and Rosenthal, 1972; Lømo and Westgaard, 1975). Our experiments on the CNS, however, produced the opposite results. We found that depolarization of the postsynaptic neuron did not attenuate the effect of denervation. In fact, rather than increasing protein synthesis, antidromic stimulation of the NM neuron enhanced the effects of deafferentation by further reducing protein synthesis beyond that seen in deafferented, unstimulated neurons. Thus, it appears that neuron-neuron regulation involves different cellular processes than neuronal regulation of other target tissues.

If liberally applied, our finding that postsynaptic activity is not sufficient to produce effects similar to those of afferent activity could have implications for understanding the cellular processes involved in other instances of transneuronal regulation. Activity-dependent changes in protein synthesis appear to be a common finding in neural tissue and has been proposed as a cellular mechanism of learning and memory (Black et al., 1987;

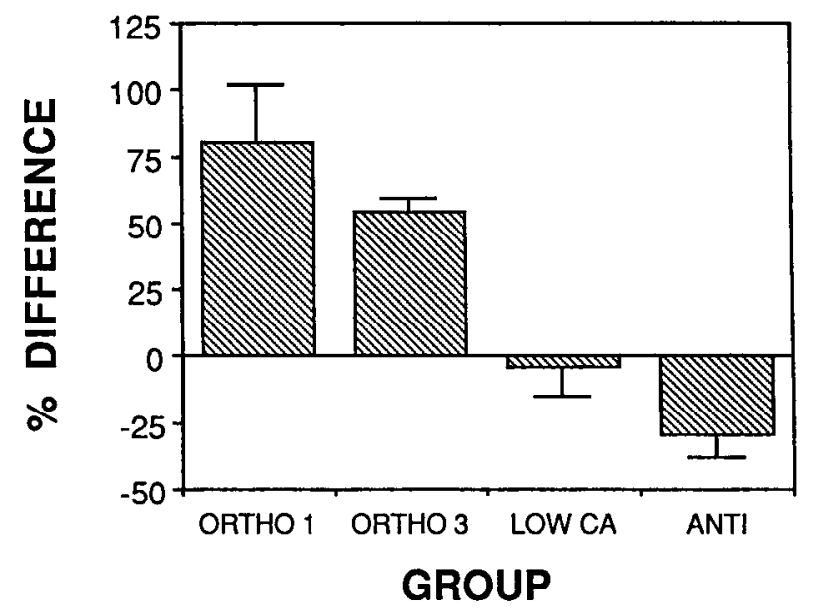

Figure 8. Mean percent difference in labeling over NM neurons on the stimulated and unstimulated sides of the slice [(stimulated - unstimulated)/unstimulated]. Bars represent SEM. ORTHO 1, Unilateral orthodromic stimulation for $1.5 \mathrm{hr} ; O R T H O 3$, unilateral orthodromic stimulation for $3.5 \mathrm{hr} ; L O W C A$, unilateral orthodromic stimulation for $1.5 \mathrm{hr}$ in a low $\mathrm{Ca}^{2+} / \mathrm{high} \mathrm{Mg}^{2+}$ medium; $A N T I$, unilateral antidromic stimulation for $1.5 \mathrm{hr}$.

Schacher et al., 1988). For example, alterations in the synthesis of specific proteins and/or messenger RNAs as a result of depolarization have been shown in sympathetic and CNS tissue (reviewed by Black et al., 1987). It is unclear, however, whether these effects are due to depolarization of the postsynaptic neurons or require the cascade of events involving the action of a trophic substance released from active presynaptic terminals. Although numerous differences exist between these experiments and those in the present report, our results suggest that depolarization per se is not sufficient to increase synthesis in the postsynaptic neuron.

In addition to the relatively subtle effects on cell metabolism, deafferentation has been shown to result in cell death in a number of systems (Levi-Montalcini, 1949; Parks, 1979; Okado and Oppenheim, 1984; Born and Rubel, 1985; Clarke, 1985; Oppenheim, 1985; Linden and Pinon, 1987). As noted earlier, one of the reasons protein synthesis was used as the assay of the effect of afferent activity was because the cessation of protein synthesis appears to predict which deafferented NM neurons will eventually die. If elimination of protein synthesis is indeed an early marker for cell death, then further understanding of the changes in protein synthesis might provide insights into mechanisms of cell death following deafferentation. Consistent with the results of the present series of experiments, regulation of cell death in other systems appears to involve synaptic transmission. For example, blockade of spontaneous activity in cultured retinal ganglion cells with TTX or by maintaining the cells in a low $\mathrm{Ca}^{2+}$ medium results in enhanced cell death (Lipton, 1986). Additionally, blockade of synaptic transmission in the ciliary ganglion enhances naturally occurring cell death (Maderdrut et al., 1988). These manipulations, however, block both synaptic transmission from the presynaptic terminal and activity of the postsynaptic neurons. If the results of the present experiments can be applied to these cases of afferent influences on cell death, they suggest that synaptic releasc from the afferent nerve terminal and not activity per se is important for survival of the postsynaptic neuron. A direct test of this hypothesis is needed. 


\section{References}

Alkon, D. L. (1984) Calcium-mediated reduction of ionic currents: A biophysical memory trace. Science $226: 1037-1045$.

Baudry, M., and G. Lynch (1980) Regulation of hippocampal glutamate receptors: Evidence for the involvement of calcium-activated pronase. Proc. Natl. Acad. Sci. USA 77: 2298-2302.

Black, I. B., J. E. Adler, C. F. Dreyfus, W. F. Friedman, E. F. LaGamma, and A. H. Roach (1987) Biochemistry of information storage in the nervous system. Science 236: 1263-1268.

Born, D. E., and E. W Rubel (1984) Cochlea removal eliminates physiological activity in brain stem auditory nuclei of the chicken. Soc. Neurosci. Abstr. 10: 843.

Born, D. E., and E. W Rubel (1985) Afferent influences on brain stem auditory nuclei of the chicken: Neuron number and size following cochlea removal. J. Comp. Neurol. 231: 435-445.

Born, D. E., and E. W Rubel (1988) Afferent influences on brain stem auditory nuclei of the chicken: Presynaptic action potentials regulate protein synthesis in nucleus magnocellularis neurons. J. Neurosci. 8 : 901-919.

Brugge, J. F., S. S. Orman, J. R. Coleman, J. C. K. Chan, and D. P. Phillips (1985) Binaural interactions in cortical area AI of cats reared with unilateral atresia of the external ear. Hear. Res. 20: 275-287.

Clarke, P. G. H. (1985) Neuronal death during development in the isthmo-optic nucleus of the chick: Sustaining afferents from the teclum. J. Comp. Neurol, 234: 365-379.

Collingeridge, G. L., S. J. Kehl, and H. McLennan (1983) Excitatory amino acids in synaptic transmission in the Schaffer-collateral-commissural pathway of the rat hippocampus. J. Physiol. (Lond.) 334: $33-46$.

Cotman, C. W., D. T. Monaghan, and A. H. Ganong (1988) Excitatory amino acid neurotransmission: NMDA and Hebb-type synaptic plasticity. Annu. Rev. Neurosci. 11: 61-80.

Cowan, W. M. (1970) Anterograde and retrograde transneuronal degeneration in the central and peripheral nervous system. In Contemporary Research Methods in Neuroanatomy, W. J. H. Nauta and S. O. E. Ebbesson, eds., pp. 217-251, Springer-Verlag, New York.

Dubin, M. W., L. A. Stark, and S. M. Archer (1986) A role for actionpotential activity in the development of neuronal connections in the kitten retinogeniculate pathway. J. Neurosci. 6: 1021-1036.

Durham, D., and E. W Rubel (1985) Afferent influences on brain stem auditory nuclei of the chicken: Succinate dehydrogenase activity following cochlea removal. J. Comp. Neurol. 231: 446-456.

Feng, A. S., and B. A. Ragowski (1980) Effects of monaural and binaural occlusion or the morphology of neurons in the medial superior olivary nucleus of the rat. Brain Res. 189: 530-534.

Globus, A. (1975) Brain morphology as a function of presynaptic morphology and activity. In The Developmental Neuropsychology of Sensory Deprivation, A. H. Riesen, ed., pp. 9-91, Academic, New York.

Gottlieb, G. (1976) The roles of experience in the development of behavior and the nervous system. In Studies on the Development of Behavior and the Nervous System, Vol. 3. G. Gottlieb, ed., pp. 2554, Academic, New York.

Guth, L. (1968) "Trophic" influences of nerve on muscle. Physiol. Rev, 48: 645-687.

Hackett, J. T., H. Jackson, and E. W Rubel (1982) Synaptic excitation of the second and third order auditory neurons in the avian brain stem. Neuroscience 7: 1455-1469.

Harris, E. W., A. H. Ganong, and C. W. Cotman (1984) Long-term potentiation in the hippocampus involves activation of N-methyl-Daspartate receptors. Brain Res. 323: 132-137.

Harris, W. A. (1981) Neural activity and development. Annu. Rev. Physiol. 43: 689-710.

Hyson, R. L., and E. W. Rubel (1988) Activation of excitatory amino acid receptors enhances protein synthesis in brain stem auditory neurons of the chick. Soc. Neurosci. Abstr. 14: 517.

Jackson, H., E. F. Nemeth, and T. N. Parks (1985) Non-N-methylD-aspartate receptors mediating synaptic transmission in avian cochlear nucleus: Effects of kynurenic acid, dipicolinic acid and streptomycin. Neuroscience 16:171-179.

Jones, D. A., and H. M.Icllwain (1971) Amino acid distribution and incorporation into proteins in isolated, electrically-stimulated cerebral tissues. J. Neurochem. $18: 41-58$.
Kandel, E. R., and J. H. Schwartz (1982) Molecular biology of learning: Modulation of transmitter release. Science 218: 433-443.

Kerr, L. M., E. M. Ostapoff, and E. W Rubel (1979) Iiffluence of acoustic experience in the ontogeny of frequency generalization gradients in the chicken. J. Exp. Psychol. [Anim. Behav.] 5: 97-1 15.

Kleinschmidt, A., M. F. Bear, and W. Singer (1988) Blockade of "NMDA" receptors disrupts experience-dependent plasticity of kitten striate cortex. Science 238: 355-358.

Knudsen, E. I., S. D. Esterly, and P. F. Knudsen (1984) Monaural occlusion alters sound localization during a sensitive period in the barn owl. J. Neurosci. 4: 1001-1011.

Lavoie, P.-A., B. Collier, and A. Tenenhouse (1977) Role of skeletal muscle activity in the control of muscle acetycholine sensitivity. Exp. Neurol. 54: 148-171.

Levi-Montalcini, R. (1949) The development of the acoustico-vestibular centers in the chick embryo in the absence of the afferent root fibers and of descending fiber tracts. J. Comp. Neurol. 91: 209-242.

Linden, R., and L. G. P. Pinon (1987) Dual control by targets and afferents of developmental neuronal death in the mammalian central nervous system: A study in the parabigeminal nucleus of the rat. $\mathrm{J}$. Comp. Neurol. 266: 141-149.

Lippe, W. R., O. Steward, and E. W Rubel (1980) The effect of unilateral basilar papilla removal upon nuclei laminaris and magnocellularis of the chick examined with $\left[{ }^{3} \mathrm{H}\right] 2$-deoxy-D-glucose autoradiography. Brain Res. 196: 43-58.

Lipton, P. (1987) Measurement of protein synthesis in hippocampal slices: In vitro versus in vivo. In Brain Slices: Fundarnentals, Applications and Implications, A. Schurr, T. J. Teyler, and M. T. Tseng, eds., pp. 45-58, Karger, Basel.

Lipton, P., and C. J. Heinbach (1978) Mechanism of extracellular potassium stimulation of protein synthesis in the in vitro hippocampus. J. Neurochem. 31: 1299-1307.

Lipton, P., and K. Robacker (1983) Glycolysis and brain function: $\left[\mathrm{K}^{+}\right]_{0}$ stimulation of protein synthesis and $\mathrm{K}^{+}$uptake require glycolysis. Fed. Proc. 42: 2875-2880.

Lipton, S. A. (1986) Blockade of electricai activity promotes the death of mammalian retinal ganglion cells in culture. Proc. Natl. Acad. Sci. USA 83: 9774-9778.

Lomo, T., and J. Rosenthal (1972) Control of ACh sensitivity by muscle activity in the rat. J. Physiol. (Lond.) 221: 493-513.

Lomo, T., and R. H. Westgaard (1975) Further studies on the control of ACh sensitivity by muscle activity in the rat. J. Physiol. (Lond.) 252: 603-626.

Maderdrut, J. L., R. W. Oppenheim, and D. Prevette (1988) Enhancement of naturally occurring cell death in the sympathetic and parasympathetic ganglia of the chicken embryo following blockade of ganglionic transmission. Brain Res. 444: 189-194.

Martin, M. R. (1985) Excitatory amino acid pharmacology of the auditory nerve and nucleus magnocellularis of the chicken. Hear. Res. 17: $153-160$.

McArdle, J. J. (1983) Molecular aspects of the trophic influence of nerve on muscle. Prog. Neurobiol. 21: 135-198.

Mistretta, C. M., and K. M. Bradley (1978) Effects of early experience on brain and behavioral development. In Studies on the Development of Behavior and the Nervous System, Vol. 4, G. Gottlieb, ed., pp. 215247 , Academic, New York.

Moore, D. R., and D. R. F. Irvine (1981) Plasticity of binaural interaction in the cat inferior colliculus. Brain Res. 208: 198-202.

Morris, R. G. M., E. Anderson, G. S. Lynch, and M. Baudry (1986) Selective impairment of learning and blockade of long-term potentiation by an $\mathrm{N}$-methyl-D-aspartate receptor antagonist, AP5. Nature 319: 774-776.

Movshon, J. A., and R. C. van Sluyters (1981) Visual neural development. Annu. Rev. Psychol. 32: 477-522.

Nemeth, E. F., H. Jackson, and T. N. Parks (1983) Pharmacological evidence for synaptic transmission mediated by non-N-methyl-Daspartate receptors in avian cochlear nucleus. Neurosci. Lett. 40:3944.

Oertel, D. (1983) Synaptic responses and electrical properties of cells in brain slices of the mouse anteroventral cochlear nucleus. J. Neurosci. 3: 2043-2053.

Oertel, D. (1985) Use of brain slices in the study of the auditory system: Spatial and temporal summation of synaptic inputs in cells in the anteroventral cochlear nucleus of the mouse. J. Acoust. Soc. Am. 78: $328-333$ 
Okado, N., and R. W. Oppenheim (1984) Cell death of motoneurons in the chick embryo spinal cord. IX. The loss of motoneurons following removal of afferent inputs. J. Neurosci. 4: 1639-1652.

Oppenheim, R. W. (1985) Naturally occurring cell death during neural development. Trends Neurosci. 17: 487-493.

Parks, T. N. (1979) Afferent influences on the development of brain stem auditory nuclei of the chicken: Otocyst ablation. J. Comp. Neurol. 183: 655-676.

Parks, T. N. (1981) Changes in the length and organization of nucleus laminaris dendrites after unilateral otocyst ablation in chick embryos. J. Comp. Neurol. 202: 47-57.

Parks, T. N., and E. W Rubel (1978) Organization and development of brain stem auditory nuclei of the chicken: Primary afferent projections. J. Comp. Neurol. 180: 439-448.

Pestronk, A., D. B. Drachman, and J. W. Griffin (1976) Effect of muscle disuse on acetylcholine receptors. Nature 260: 352-353.

Rogers, A. W. R. (1979) Techniques of Autoradiography, Elsevier, Amsterdam.

Rubel, E. W, and G. H. MacDonald (1987) Rapid proliferation of glial processes following deafferentation in nucleus magnocellularis in neonatal chickens. Soc. Neurosci. Abstr. 13: 80.

Schacher, S., V. Castellucci, and E. R. Kandel (1988) cAmp evokes long-term facilitation in Aplysia sensory neurons that require new protein synthesis. Science 240: 1667-1669.

Sherman, S. M., and P. D. Spear (1982) Organization of visual path- ways in normal and visually deprived cats. Physiol. Rev. 62: 738885.

Smith, Z. D. J., L. Gray, and E. W Rubel (1983) Afferent influences on brainstem auditory nuclei of the chicken: $N$. laminaris dendritic length following monaural conductive hearing loss. J. Comp. Neurol. 220: 199-205.

Steward, O., and E. W Rubel (1985) Afferent influences on brain stem auditory nuclei of the chicken: Cessation of amino acid incorporation as an antecedent to age-dependent transneuronal degeneration. $\mathrm{J}$. Comp. Neurol. 231: 385-395.

Stryker, M. P., and W. A. Harris (1986) Binocular impulse blockage prevents the formation of ocular dominance columns in cat visual cortcx. J. Neurosci. 6: 2117-2133.

Tucci, D. L., D. E. Born, and E. W Rubel (1987) Changes in spontaneous activity and CNS morphology associated with conductive hearing loss in chickens. Ann. Otol. Rhinol. Laryngol. 96: 343-350.

Webster, D. B., and M. Webster (1977) Neonatal sound deprivation affects brain stem auditory nuclei. Arch. Otolaryngol. 103: 392-396.

Weisel, T. N., and D. H. Hubel (1963) Effects of visual deprivation on morphology and physiology of cells in the cat's lateral geniculate body. J. Neurophysiol. 26: 978-993.

Weisel, T. N., and D. H. Hubel (1965) Comparison of the effects of unilateral and bilateral eye closure on cortical unit responses in kittens. J. Neurophysiol. 28: 1029-1040. 